\title{
Dysphasia is associated with diffusion-weighted MRI abnormalities in patients with transient neurological symptoms
}

\author{
Zejin Jia $^{1} \cdot$ Yangguang Song ${ }^{2} \cdot$ Wenli Hu ${ }^{1}$ (D) \\ Received: 21 October 2019 / Accepted: 15 January 2020 / Published online: 7 February 2020 \\ (C) The Author(s) 2020
}

\begin{abstract}
Background The clinical characteristics of diffusion-weighted imaging (DWI) abnormalities after transient neurological symptoms are of great significance for the early diagnosis and urgent intervention of transient ischemic attack (TIA). This study was aimed to investigate the clinical characteristics associated with acute DWI lesions in transient neurological symptoms.

Methods We retrospectively recruited 302 patients with transient neurological symptoms. According to DWI findings, they were divided into DWI positive and DWI negative group. The clinical characteristics and the TIA-related scores such as ABCD2, ABCD3, ABCD3I, Dawson score, and the Diagnosis of TIA (DOT) score were compared between the two groups. Logistic regression analysis and receiver operating characteristic curves were used to identify the independent factors and compare the predictive value of different TIA scores for acute DWI lesions.

Results A total of 302 patients were enrolled in this study. The mean age was 61.8 years, and $67.2 \%$ were male. We found 89 (29.5\%) patients with DWI positivity. Logistic regression analysis showed the characteristic associated with DWI lesions was dysphasia (OR 2.226, 95\% CI 1.220-4.062). The area under the curve for Dawson score and the DOT score was 0.610 (95\% CI $0.543-0.678$ ) and 0.625 (95\% CI 0.559-0.691), respectively.

Conclusion We found that DWI lesions were detected in $29.5 \%$ of patients with transient neurological symptoms and were associated with dysphasia. Dawson score and DOT score could have a higher predictability of DWI lesions in patients with transient neurological symptoms.
\end{abstract}

Keywords Transient neurological symptoms · Diffusion-weighted imaging · Acute ischemic lesions · Dawson score $\cdot$ The Diagnosis of TIA score

\section{Introduction}

A new tissue-based definition of transient ischemic attack (TIA) is a transient episode of focal neurological deficits consistent with cerebrovascular accident lasting less than $24 \mathrm{~h}$ and with the absence of a diffusion-weighted imaging (DWI) lesion detected by MRI [1-4]. TIA is treated as a medical emergency and may precede ischemic stroke that causes permanent neurological deficits. The stroke risk after TIA may be as high as $10 \%$ in the first week [5]. Identifying and treating patients

Wenli $\mathrm{Hu}$

huwenli@sina.com

1 Department of Neurology, Beijing Chaoyang Hospital, Capital Medical University, Beijing 100020, China

2 Department of Pathology, Beijing Chaoyang Hospital, Capital Medical University, Beijing 100020, China with TIA is an effective way to prevent stroke [6]. DWI is a mandatory tool in the diagnosis of a TIA [7]. However, in many emergency settings, patients with transient neurological symptoms are difficult to have urgent brain MRI due to cost issues [8]. Several studies have shown that diffusion-weighted imaging (DWI) lesions were associated with a high risk of recurrent ischemic stroke after transient neurological symptoms [9-11]. The frequency of positive DWI findings in patients with transient neurological symptoms varied from 9 to $67 \%$ in some prior studies [12]. The clinical features associated with DWI lesions after transient neurological symptoms are of great significance for the early diagnosis and urgent intervention of TIA [13]. It has been reported that the presence of acute DWI lesions in transient neurological symptoms were associated with motor weakness, aphasia, dysarthria, left hemispheric presenting symptoms, National Institutes of Health Stroke Scale (NIHSS) score of $\geq 10$ at admission, time from onset to DWI longer than $24 \mathrm{~h}$, intracranial large artery 
atherosclerosis, and old brain infarctions on MRI [14-17]. However, as for the incidence of positive DWI in Chinese patients with transient neurological symptoms and its' independent predictors for this positive DWI are poorly understood.

Recently, the Diagnosis of TIA (DOT) score has been proposed [18]. It is a new and internally validated web and mobile app-based diagnostic tool which encompasses both brain and retinal TIA. However, as a promising diagnostic tool for TIA, DOT score still needs independent external validation before it can be widely utilized.

Thus, our study was aimed to investigate the clinical characteristics associated with the presence of acute DWI lesions in Chinese patients with transient neurological symptoms and tested the validation of DOT score in China.

\section{Methods}

\section{Patients}

We retrospectively identified patients with transient neurological symptoms lasting less than $24 \mathrm{~h}$, who were admitted to the neurology department of Beijing Chaoyang Hospital, Capital Medical University from January 2016 to February 2019. All the patients underwent DWI within 5 days after admission. We used a 3.0-T MRI to evaluate whether acute ischemic lesions were present on admission. Sequences included diffusion-weighted, T1-weighted, and T2-weighted imaging; fluid-attenuated inversion recovery (FLAIR); and magnetic resonance angiography (MRA). Acute DWI lesions were defined by the areas of high signal intensity on DWI with restricted diffusion. All MRI scans were read by experienced neuroradiologists. Based on the results of DWI, patients were divided into two groups: DWI-positive and DWI-negative group.

We collected a broad range of clinical, laboratory, and radiological data from all patients: the baseline characterizations such as age and gender, clinical symptoms, duration of symptoms, time from onset to MRI, vascular risk factors including hypertension, diabetes mellitus, atrial fibrillation, hyperlipidemia, smoking and alcohol drinking, history of ischemic stroke and coronary artery disease, ABCD2 [19], ABCD3, ABCD3I [20], Dawson score [21], DOT score [18] at admission, the laboratory blood tests on admission recorded for platelet count(PLT), albumin(ALB), prealbumin(PAB), cholesterol(CHOL), low-density lipoprotein(LDL), triglyceride(TG), blood urea nitrogen(BUN), creatinine $(\mathrm{Cr})$, uremic acid(URIC), calcium $(\mathrm{Ca})$, phosphonium $(\mathrm{P})$, fibrinogen $(\mathrm{Fbg})$, fasting blood-glucose(FBG), degree of cerebral artery stenosis in MRA and computed tomographic angiography(CTA), the intimal medial thickness(IMT) of carotid artery in carotid duplex ultrasonography, and treatment after admission. The degree of carotid and intracranial arterial stenosis was classified as over $25 \%, 50 \%$, and $75 \%$ narrowing and occlusion.

The study was approved by the ethics committee of Beijing Chaoyang Hospital and performed in accordance with the Declaration of Helsinki. All subjects provided written informed consent.

\section{Statistics analysis}

Statistical analyses were performed using IBM SPSS Statistics 21. All statistics were presented as mean \pm standard deviation (SD) for continuous variables with normal distribution, the median and interquartile range for continuous variables with non-normal distribution, and counts and proportions for categorical variables. We performed $t$ test, chi-square test, and the nonparametric Mann-Whitney U test to compare the characteristics between the two groups. A $P$ value of less than 0.05 was considered significant. Logistic regression analysis was applied to identify independent predictors of acute DWI lesions in patients with transient neurological symptoms. The results were presented as estimates of relative risk by odds ratio (OR) with a 95\% confidence interval (CI). Receiver operating characteristic curve (ROC) analysis was used to compare the predictive values of various scores with regard to acute DWI lesions in patients with transient neurological symptoms.

\section{Results}

We retrospectively recruited 302 patients with transient neurological symptoms who underwent DWI within 5 days after admission. DWI lesions were detected in 89 (29.5\%) of the 302 patients. Table 1 shows the clinical characteristics of DWI-positive and DWI-negative group at baseline. The results of blood pressure on admission, the laboratory blood tests, the other examination, and the scores of TIA with the two groups are presented in Table 2.

There were significant differences in gender, dysphasia, motor weakness, hyperlipidemia, smoking, alcohol drinking, systolic pressure, diastolic pressure, platelet count, FBG, and the severity of intracranial stenosis between the two groups. Besides, the DWI-positive group had a higher level of IMT of the carotid artery. Logistic regression analysis showed that acute DWI lesions were independently correlated with dysphasia (OR 2.226, 95\% CI 1.220-4.062) (Table 3).

In addition, the $\mathrm{ABCD} 2, \mathrm{ABCD} 3, \mathrm{ABCD} 3 \mathrm{I}$, Dawson score, and DOT score were significantly higher in DWIpositive group than DWI-negative group. Based on ROC curve analysis (Fig. 1), the comparison of under the curve 
Table 1 The baseline clinical characteristics of patients in DWIpositive and DWI-negative group

\begin{tabular}{|c|c|c|c|}
\hline Variables & DWI-positive $(n=89)$ & DWI-negative $(n=213)$ & $P$ value \\
\hline Age, years & $62(53,69)$ & $63(55.5,70.5)$ & 0.430 \\
\hline Male, $n(\%)$ & $71(79.8 \%)$ & $132(62 \%)$ & $0.003^{\mathrm{a}}$ \\
\hline \multicolumn{4}{|l|}{ Risk factors, $n(\%)$} \\
\hline Hypertension & $57(64 \%)$ & $136(63.8 \%)$ & 1.000 \\
\hline Diabetes mellitus & $30(33.7 \%)$ & $61(28.6 \%)$ & 0.410 \\
\hline Coronary artery disease & $6(6.7 \%)$ & $24(11.3 \%)$ & 0.294 \\
\hline Hyperlipidemia & $72(80.9 \%)$ & $146(68.5 \%)$ & $0.034^{\mathrm{a}}$ \\
\hline History of stroke & $16(18.0 \%)$ & $43(20.2 \%)$ & 0.751 \\
\hline Atrial fibrillation & $2(2.2 \%)$ & $7(3.3 \%)$ & 1.000 \\
\hline Smoking & $56(62.9 \%)$ & $91(42.7 \%)$ & $0.002^{\mathrm{a}}$ \\
\hline Alcohol drinking & $35(39.3 \%)$ & $49(23 \%)$ & $0.005^{\mathrm{a}}$ \\
\hline \multicolumn{4}{|l|}{ Clinical features, $\mathrm{n}(\%)$} \\
\hline Motor weakness & $62(69.7 \%)$ & $119(55.9 \%)$ & $0.029^{\mathrm{a}}$ \\
\hline Dysphasia & $43(48.3 \%)$ & $63(29.6 \%)$ & $0.002^{\mathrm{a}}$ \\
\hline Sensory disturbance & $29(32.6 \%)$ & $72(33.8 \%)$ & 0.894 \\
\hline Dizziness & $29(32.6 \%)$ & $67(31.5 \%)$ & 0.892 \\
\hline Ataxia & $2(2.2 \%)$ & $13(6.1 \%)$ & 0.245 \\
\hline Amnesia & $4(4.5 \%)$ & $4(1.9 \%)$ & 0.241 \\
\hline Loss of consciousness & $5(5.6 \%)$ & $19(8.9 \%)$ & 0.484 \\
\hline Diplopia & $5(5.6 \%)$ & $10(4.7 \%)$ & 0.774 \\
\hline Homonymous hemianopia & $3(3.4 \%)$ & $5(2.3 \%)$ & 0.697 \\
\hline Time from TIA to MRI, days & $4.5(3,9.25)$ & $6(3,11)$ & 0.161 \\
\hline Symptom duration, $n(\%)$ & & & 0.238 \\
\hline$<10 \min$ & $33(37.1 \%)$ & $99(47.4 \%)$ & \\
\hline $10-59 \mathrm{~min}$ & $39(43.8 \%)$ & $73(34.9 \%)$ & \\
\hline$>60 \mathrm{~min}$ & $17(19.1 \%)$ & $37(17.7 \%)$ & \\
\hline Treatment, $n(\%)$ & & & $0.000^{\mathrm{a}}$ \\
\hline Aspirin & $24(27 \%)$ & $80(44.9 \%)$ & \\
\hline Clopidogrel & $10(11.2 \%)$ & $51(28.7 \%)$ & \\
\hline Dual antiplatelet & $54(60.1 \%)$ & $43(24.2 \%)$ & \\
\hline Anticoagulation & $1(1.1 \%)$ & $4(2.2 \%)$ & \\
\hline
\end{tabular}

Data shown: median (interquartile range) or counts (\%)

DWI, diffusion-weighted imaging

${ }^{\text {a }} P$ value less than 0.05
(AUC) showed superiority of Dawson score (0.610 (95\% CI, 0.543-0.678)) and DOT score (0.625 (95\% CI, 0.559-0.691)) compared with the ABCD2 score (0.585 (95\% CI, 0.517$0.654)$ ) and ABCD3 score (0.609 (95\% CI, 0.540-0.678)) (Table 4). ABCD3I score was superior to all other scores (0.83 (95\% CI, 0.779-0.881)). The corresponding cutoff values are shown in Table 4. The cutoff values of the ABCD3 score and the DOT score was 5.5 and 0.079 , respectively.

In addition, we also found that most of the DWI lesions were located in the periventricular area, basal ganglia, and cortical and subcortical regions. Most lesions were diffused punctiform lesions or lacunar infarcts. DWI lesions were more frequent in the anterior circulation.

\section{Discussion}

In our present study, our findings showed that DWI lesions were detected in $29.5 \%$ of Chinese patients with transient neurological symptoms. The clinical characteristic associated with DWI lesions was dysphasia. The ABCD2, ABCD3, ABCD3I, Dawson score, and DOT score were significantly higher in the DWI-positive group. The ABCD3I score was superior to all other scores, and the AUC of ABCD3I and DOT score were 0.83 and 0.63 , respectively.

The frequency of positive DWI findings was different, which varied from 9 to $67 \%$ in patients with transient neurological symptoms in prior studies [12]. In young patients, about $15 \%$ of whom demonstrated acute DWI lesions 
Table 2 Results of blood pressure, laboratory tests, examinations, and the TIA-related scores

\begin{tabular}{|c|c|c|c|}
\hline Variables & DWI-positive $(n=89)$ & DWI-negative $(n=213)$ & $P$ value \\
\hline Systolic pressure, $\mathrm{mmHg}$ & $151.78 \pm 19.119$ & $145.06 \pm 20.457$ & $0.008^{\mathrm{a}}$ \\
\hline Diastolic pressure, $\mathrm{mmHg}$ & $86(78.5,92.5)$ & $80(73,89.5)$ & $0.002^{\mathrm{a}}$ \\
\hline $\mathrm{PLT}, * 10^{\wedge} 9 / \mathrm{L}$ & $200.60 \pm 50.27$ & $216.29 \pm 47.65$ & $0.012^{\mathrm{a}}$ \\
\hline ALB, g/L & $42.3(39.95,44.25)$ & $41.9(39.125,44.5)$ & 0.679 \\
\hline $\mathrm{PAB}, \mathrm{g} / \mathrm{L}$ & $0.25(0.21,0.295)$ & $0.25(0.2,0.29)$ & 0.426 \\
\hline $\mathrm{CHOL}, \mathrm{mmol} / \mathrm{L}$ & $4.57(3.78,5.095)$ & $4.455(3.848,5.36)$ & 0.569 \\
\hline $\mathrm{LDL}, \mathrm{mmol} / \mathrm{L}$ & $2.8(1.95,3.2)$ & $2.6(2,3.275)$ & 0.873 \\
\hline $\mathrm{TG}, \mathrm{mmol} / \mathrm{L}$ & $1.66(1.145,2.365)$ & $1.46(1.06,2.225)$ & 0.206 \\
\hline $\mathrm{BUN}, \mathrm{mmol} / \mathrm{L}$ & $5.11(4.34,5.92)$ & $4.93(4.405,5.952)$ & 0.908 \\
\hline $\mathrm{Cr}$, umol/L & $67.7(59.8,80)$ & $66.5(55.775,74.875)$ & 0.127 \\
\hline URIC, umol/L & $330.73 \pm 88.602$ & $338.53 \pm 86.554$ & 0.479 \\
\hline $\mathrm{Ca}, \mathrm{mmol} / \mathrm{L}$ & $2.253 \pm 0.132$ & $2.266 \pm 0.134$ & 0.474 \\
\hline $\mathrm{P}, \mathrm{mmol} / \mathrm{L}$ & $1.064 \pm 0.242$ & $1.108 \pm 0.220$ & 0.121 \\
\hline $\mathrm{Fbg}, \mathrm{mg} / \mathrm{dl}$ & $256.3(229.5,309.4)$ & $270.3(228.9,306.2)$ & 0.428 \\
\hline $\mathrm{FBG}, \mathrm{mmol} / \mathrm{L}$ & $6.27(5.045,8.565)$ & $5.55(4.7,7.055)$ & $0.006^{\mathrm{a}}$ \\
\hline \multicolumn{3}{|l|}{ Carotid stenosis, $n(\%)$} & \multirow[t]{6}{*}{0.179} \\
\hline No stenosis & $55(64.0 \%)$ & $153(74.3 \%)$ & \\
\hline Mild stenosis & $15(17.4 \%)$ & $28(13.6 \%)$ & \\
\hline Moderate stenosis & $6(7.0 \%)$ & $13(6.3 \%)$ & \\
\hline Severe stenosis & $9(10.5 \%)$ & $8(3.9 \%)$ & \\
\hline Occlusion & $1(1.2 \%)$ & $4(1.9 \%)$ & \\
\hline \multicolumn{3}{|c|}{ Intracranial arterial stenosis, $n(\%)$} & \multirow[t]{6}{*}{$0.016^{\mathrm{a}}$} \\
\hline No stenosis & $30(34.9 \%)$ & $117(56.8 \%)$ & \\
\hline Mild stenosis & $20(23.3 \%)$ & $33(16.0 \%)$ & \\
\hline Moderate stenosis & $10(11.6 \%)$ & $19(9.2 \%)$ & \\
\hline Severe stenosis & $11(12.8 \%)$ & $17(8.3 \%)$ & \\
\hline Occlusion & $15(17.4 \%)$ & $20(9.7 \%)$ & \\
\hline IMT, cm & $0.28(0.240,0.368)$ & $0.255(0.180,0.370)$ & $0.038^{\mathrm{a}}$ \\
\hline $\mathrm{ABCD} 2$ score & $4(3,5)$ & $4(3,5)$ & $0.018^{\mathrm{a}}$ \\
\hline $\mathrm{ABCD} 3$ score & $5(4,6)$ & $5(3,6)$ & $0.002^{\mathrm{a}}$ \\
\hline $\mathrm{ABCD} 3 \mathrm{I}$ score & $8(6,9)$ & $5(3,6)$ & $0.000^{\mathrm{a}}$ \\
\hline Dawson score & $7.55 \pm 1.29$ & $7.04 \pm 1.43$ & $0.004^{\mathrm{a}}$ \\
\hline DOT score & $1.341(0.352,3.717)$ & $0.842(-1.407,2.185)$ & $0.001^{\mathrm{a}}$ \\
\hline
\end{tabular}

Data shown: mean \pm standard deviation, median (interquartile range) or counts (\%)

$D W I$, diffusion-weighted imaging; $P L T$, platelet count; $A L B$, albumin; $P A B$, prealbumin; $C H O L$, cholesterol; $L D L$, low density lipoprotein; $T G$, triglyceride; $B U N$, blood urea nitrogen; $C r$, creatinine; URIC, uremic acid; $C a$, calcium; $P$, phosphonium; Fbg, fibrinogen; $F B G$, fasting blood-glucose; $I M T$, the intimal medial thickness; DOT score, the Diagnosis of TIA score

${ }^{\text {a }} P$ value less than 0.05

according to brain MRI [16]. In our study, the frequency of an acute DWI lesion was $29.5 \%$, which was consistent with the above prior studies. In our study, there were no differences in the time from onset to DWI examination between the two groups. A potential cause for heterogeneity of the incidence of positive DWI may be the time from symptom onset to DWI examination. A meta-analysis indicated that there was no evidence that the DWI-positive rate varied with time from symptom onset to DWI examination, but it was found that DWI lesions may disappear within $24 \mathrm{~h}$ or be undetectable on hyperacute imaging [12]. The study of Shono K also demonstrated that short latency (less than $2 \mathrm{~h}$ ) from symptom onset to initial DWI was an independent risk factor associated with false-negative findings on DWI [22]. As a result, a repeated DWI examination is recommended for these patients with transient neurological symptoms. Further research is needed to define the relationship between DWI lesions and the time from symptom onset to examination.

Additionally, our study also found that acute DWI lesions were associated with dysphasia, which was also in agreement 
Table 3 Clinical symptoms associated with DWI lesions in logistic regression analysis

\begin{tabular}{llll}
\hline Factors & OR & $95 \%$ CI & $P$ value \\
\hline Dysphasia & 2.226 & $1.220,4.062$ & $0.009^{\mathrm{a}}$ \\
Male & 1.494 & $0.634,3.521$ & 0.358 \\
Hypertension & 0.758 & $0.399,1.441$ & 0.398 \\
Diabetes mellitus & 1.066 & $0.505,2.250$ & 0.867 \\
Coronary artery disease & 0.393 & $0.120,1.291$ & 0.124 \\
Hyperlipidemia & 1.609 & $0.805,3.215$ & 0.178 \\
History of stroke & 0.815 & $0.378,1.760$ & 0.603 \\
Atrial fibrillation & 0.472 & $0.044,5.067$ & 0.536 \\
Smoking & 1.294 & $0.604,2.772$ & 0.508 \\
Alcohol drinking & 1.155 & $0.566,2.355$ & 0.692 \\
Systolic pressure & 1.012 & $0.993,1.032$ & 0.209 \\
Diastolic pressure & 1.015 & $0.985,1.045$ & 0.345 \\
PLT & 0.994 & $0.987,1.000$ & 0.051 \\
LDL & 0.825 & $0.592,1.150$ & 0.256 \\
Fbg & 0.999 & $0.995,1.003$ & 0.543 \\
FBG & 1.069 & $0.963,1.186$ & 0.211 \\
Carotid stenosis & 1.137 & $0.829,1.560$ & 0.426 \\
Intracranial stenosis & 1.222 & $0.990,1.508$ & 0.062 \\
\hline
\end{tabular}

$D W I$, diffusion-weighted imaging; $P L T$, platelet count; $L D L$, low density lipoprotein; $F b g$, fibrinogen; $F B G$, fasting blood-glucose

${ }^{\text {a }} P$ value less than 0.05

with previous investigations [14]. To date, the diagnosis of TIA is mainly based on detailed history-taking, thus, the diagnosis of TIA can be difficult and 50-60\% of patients seen in TIA clinics turn out to be nonvascular mimics [18]. This may explain why dysphasia is an important underlying factor to be focused on. Episodes of acute atypical or nonfocal

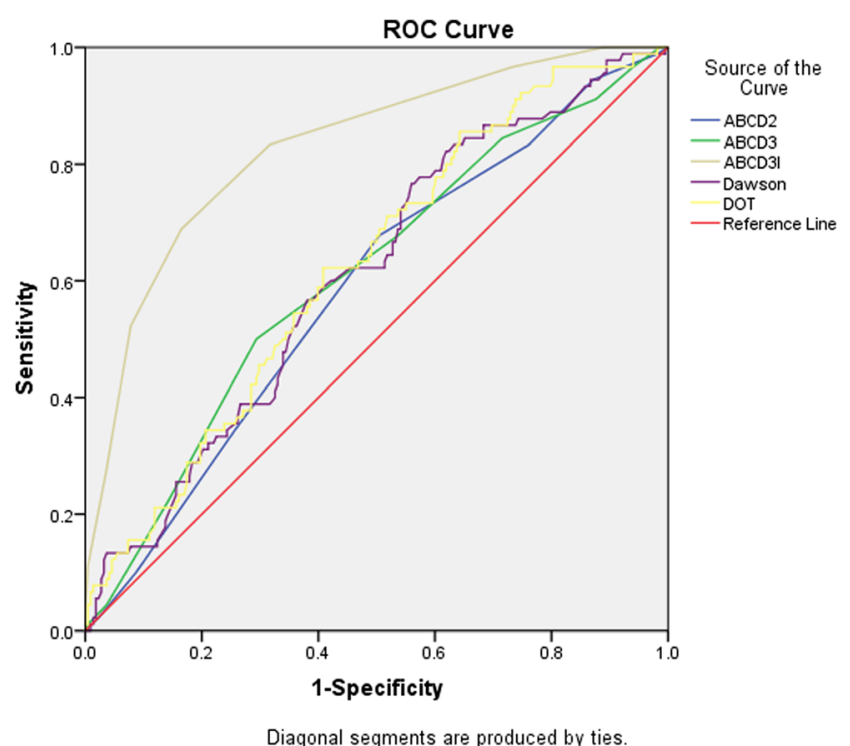

Fig. 1 Receiver operating characteristic curve analysis for various scores. DOT, the Diagnosis of TIA score. neurological symptoms referred to as transient neurological attack (TNA) are as prevalent as TIA. It was reported that DWI showed acute lesions in $23 \%$ of patients clinically diagnosed as TNA by experienced stroke neurologists [23]. This raises questions about the accuracy of the clinical diagnosis of TIA. As a result, patients with dysphasia should be taken seriously.

Our result also showed that $\mathrm{ABCD} 2, \mathrm{ABCD} 3, \mathrm{ABCD} 3 \mathrm{I}$, Dawson score, and DOT score were significantly higher in DWI-positive group. Furthermore, DWI-positive group had more severe vascular stenosis and a higher level of IMT. In our study, based on ROC, the comparison of AUC showed the superiority of the Dawson score and DOT score compared with the $\mathrm{ABCD} 2$ score and the $\mathrm{ABCD} 3$ score. The Dawson score is a clinical scoring system that assists with the diagnosis of TIA [21], which was not designed for retinal and some posterior circulation events. The DOT score is a new clinical diagnostic tool for both brain and retinal TIA [18]. With the use of the Dawson and DOT scores, the diagnosis of TIA could be more accurate. It seems to be useful to predict the acute ischemic lesions on DWI with transient neurological symptoms. In addition, our study showed that the ABCD3I score was superior to all other scores. Therefore, the DOT score and $\mathrm{ABCD} 3 \mathrm{I}$ score may play an important role in the diagnosis of TIA and assessing the risk of early stroke after TIA in Chinese patients.

The strengths of our study were shown as follows. Firstly, we investigated the incidence of positive DWI in Chinese patients with transient neurological symptoms and identified the independent predictors including laboratory tests and examinations for this positive DWI. Secondly, we validated the DOT score in the Chinese population. DOT score could have a higher predictability of DWI lesions in patients with transient neurological symptoms. Thirdly, the TIA-related scores including $\mathrm{ABCD} 2, \mathrm{ABCD} 3, \mathrm{ABCD} 3 \mathrm{I}$, Dawson score, and DOT score were compared in our study.

Our study also has several limitations. First, the samples were small, and our study population was based on hospital patients in a single-center, and there might have been selection bias. A study with a larger number of patients from multiple centers is needed to confirm the characteristics associated with

Table 4 Receiver operating characteristic curve analysis for various scores

\begin{tabular}{lllll}
\hline Test result variable (s) & Area & $95 \%$ CI & $P$ value & Cutoff \\
\hline ABCD2 & 0.585 & $0.517,0.654$ & 0.019 & 3.5 \\
ABCD3 & 0.609 & $0.540,0.678$ & 0.003 & 5.5 \\
ABCD3I & 0.830 & $0.779,0.881$ & 0.000 & 6.5 \\
Dawson & 0.610 & $0.543,0.678$ & 0.002 & 6.81 \\
DOT & 0.625 & $0.559,0.691$ & 0.001 & 0.079 \\
\hline
\end{tabular}

$D W I$, diffusion-weighted imaging; DOT, the Diagnosis of TIA score 
DWI lesions. Second, besides DWI, it was reported that perfusion-weighted imaging (PWI) is useful in defining whether or not the transient neurological symptoms in DWInegative TIA are true vascular events. The presence of a focal perfusion abnormality is a strong predictor of new DWI lesions at follow-up in DWI-negative TIA patients [24]. We need a variety of imaging tools to determine potential mechanisms underlying such events.

\section{Conclusion}

Our results showed that acute DWI lesions were detected in $29.5 \%$ of patients with transient neurological symptoms. Acute DWI lesions were associated with dysphasia. The Dawson score and DOT score may be useful for the early diagnosis and management of TIA. The characteristics associated with DWI lesions need to be confirmed in further studies.

Acknowledgments The authors thank all the study participants.

\section{Compliance with ethical standards}

The study was approved by the ethics committee of Beijing Chaoyang Hospital and performed in accordance with the Declaration of Helsinki. All subjects provided written informed consent.

Conflict of interest The authors declare that they have no conflict of interest.

Open Access This article is licensed under a Creative Commons Attribution 4.0 International License, which permits use, sharing, adaptation, distribution and reproduction in any medium or format, as long as you give appropriate credit to the original author(s) and the source, provide a link to the Creative Commons licence, and indicate if changes were made. The images or other third party material in this article are included in the article's Creative Commons licence, unless indicated otherwise in a credit line to the material. If material is not included in the article's Creative Commons licence and your intended use is not permitted by statutory regulation or exceeds the permitted use, you will need to obtain permission directly from the copyright holder. To view a copy of this licence, visit http://creativecommons.org/licenses/by/4.0/.

\section{References}

1. Albers GW, Caplan LR, Easton JD, Fayad PB, Mohr JP, Saver JL, Sherman DG (2002) Transient ischemic attack-proposal for a new definition. N Engl J Med 347:1713-1716

2. Kernan WN, Ovbiagele B, Black HR, Bravata DM, Chimowitz MI, Ezekowitz MD, Fang MC, Fisher M, Furie KL, Heck DV, Johnston SC, Kasner SE, Kittner SJ, Mitchell PH, Rich MW, Richardson D, Schwamm LH, Wilson JA (2014) Guidelines for the prevention of stroke in patients with stroke and transient ischemic attack: a guideline for healthcare professionals from the American Heart Association/American Stroke Association. Stroke 45:2160-2236
3. Furie KL, Kasner SE, Adams RJ, Albers GW, Bush RL, Fagan SC, Halperin JL, Johnston SC, Katzan I, Kernan WN, Mitchell PH, Ovbiagele B, Palesch YY, Sacco RL, Schwamm LH, WassertheilSmoller S, Turan TN, Wentworth D (2011) Guidelines for the prevention of stroke in patients with stroke or transient ischemic attack: a guideline for healthcare professionals from the American Heart Association/American Stroke Association. Stroke 42:227-276

4. Easton JD, Saver JL, Albers GW, Alberts MJ, Chaturvedi S, Feldmann E, Hatsukami TS, Higashida RT, Johnston SC, Kidwell CS, Lutsep HL, Miller E, Sacco RL (2009) Definition and evaluation of transient ischemic attack: a scientific statement for healthcare professionals from the American Heart Association/ American Stroke Association Stroke Council; Council on Cardiovascular Surgery and Anesthesia; Council on Cardiovascular Radiology and Intervention; Council on Cardiovascular Nursing; and the Interdisciplinary Council on Peripheral Vascular Disease. The American Academy of Neurology affirms the value of this statement as an educational tool for neurologists. Stroke 40: 2276-2293

5. Rothwell PM, Giles MF, Chandratheva A, Marquardt L, Geraghty O, Redgrave JN, Lovelock CE, Binney LE, Bull LM, Cuthbertson FC, Welch SJ, Bosch S, Alexander FC, Carasco-Alexander F, Silver LE, Gutnikov SA, Mehta Z (2007) Effect of urgent treatment of transient ischaemic attack and minor stroke on early recurrent stroke (EXPRESS study): a prospective population-based sequential comparison. Lancet (London, England) 370: 1432-1442

6. Fitzpatrick T, Gocan S, Wang CQ, Hamel C, Bourgoin A, Dowlatshahi D, Stotts G, Shamy M (2019) How do neurologists diagnose transient ischemic attack: a systematic review. International journal of stroke : official journal of the International Stroke Society 14:115-124

7. Hotter B, Galinovic I, Kunze C, Brunecker P, Jungehulsing GJ, Villringer A, Endres M, Villringer K, Fiebach JB (2019) Highresolution diffusion-weighted imaging identifies ischemic lesions in a majority of transient ischemic attack patients. Ann Neurol 86: 452-457

8. Altavilla R, Anticoli S, Venti MP, Acciarresi M, Alberti A, Caso VD, Amore C, Pezzella FR, Venti M, Agnelli G, Paciaroni M (2018) Clinical skills or high-tech MR in TIA patients: what makes the difference? Neurological sciences : official journal of the Italian Neurological Society and of the Italian Society of Clinical Neurophysiology 39:2091-2096

9. Kono Y, Shimoyama T, Sengoku R, Omoto S, Mitsumura H, Mochio S, Iguchi Y (2014) Clinical characteristics associated with abnormal diffusion-weighted images in patients with transient cerebral ischemic attack. J Stroke Cerebrovasc Dis 23:1051-1055

10. Engelter ST, Amort M, Jax F, Weisskopf F, Katan M, Burow A, Bonati LH, Hatz F, Wetzel SG, Fluri F, Lyrer PA (2012) Optimizing the risk estimation after a transient ischaemic attack - the $\mathrm{ABCDE} \oplus$ score. Eur J Neurol 19:55-61

11. Redgrave JN, Schulz UG, Briley D, Meagher T, Rothwell PM (2007) Presence of acute ischaemic lesions on diffusion-weighted imaging is associated with clinical predictors of early risk of stroke after transient ischaemic attack. Cerebrovascular diseases (Basel, Switzerland) 24: 86-90

12. Brazzelli M, Chappell FM, Miranda H, Shuler K, Dennis M, Sandercock PA, Muir K, Wardlaw JM (2014) Diffusion-weighted imaging and diagnosis of transient ischemic attack. Ann Neurol 75: $67-76$

13. Pvon W-M, Johnsen SP, Andersen G (2011) Low risk of vascular events following urgent treatment of transient ischaemic attack: the Aarhus TIA study. Eur J Neurol 18:1285-1290

14. Al-Khaled M, Matthis C, Munte TF, Eggers J (2013) The incidence and clinical predictors of acute infarction in patients with transient ischemic attack using MRI including DWI. Neuroradiology 55: $157-163$ 
15. Miyagi T, Uehara T, Kimura K, Okada Y, Hasegawa Y, Tanahashi N, Suzuki A, Takagi S, Nakagawara J, Arii K, Nagahiro S, Ogasawara K, Nagao T, Uchiyama S, Matsumoto M, Iihara K, Toyoda K, Minematsu K (2013) Examination timing and lesion patterns in diffusion-weighted magnetic resonance imaging of patients with classically defined transient ischemic attack. J Stroke Cerebrovasc Dis 22:e310-e316

16. Tanislav C, Grittner U, Fazekas F, Thijs V, Tatlisumak T, Huber R, Bvon S, Putaala J, Schmidt R, Kropp P, Norrving B, Martus P, Gramsch C, Giese AK, Rolfs A, Enzinger C (2016) Frequency and predictors of acute ischaemic lesions on brain magnetic resonance imaging in young patients with a clinical diagnosis of transient ischaemic attack. Eur J Neurol 23:1174-1182

17. Lodha N, Patel P, Harrell J, Casamento-Moran A, Zablocki V, Christou EA, Poisson SN (2019) Motor impairments in transient ischemic attack increase the odds of a positive diffusion-weighted imaging: a meta-analysis. Restor Neurol Neurosci 37:509-521

18. Dutta D (2016) Diagnosis of TIA (DOT) score-design and validation of a new clinical diagnostic tool for transient ischaemic attack. BMC Neurol 16:20

19. Johnston SC, Rothwell PM, Nguyen-Huynh MN, Giles MF, Elkins JS, Bernstein AL, Sidney S (2007) Validation and refinement of scores to predict very early stroke risk after transient ischaemic attack. Lancet (London, England) 369: 283-292

20. Merwick A, Albers GW, Amarenco P, Arsava EM, Ay H, Calvet D, Coutts SB, Cucchiara BL, Demchuk AM, Furie KL, Giles MF,
Labreuche J, Lavallée PC, Mas JL, Olivot JM, Purroy F, Rothwell PM, Saver JL, Sheehan OC, Stack JP, Walsh C, Kelly PJ (2010) Addition of brain and carotid imaging to the $\mathrm{ABCD}^{2}$ score to identify patients at early risk of stroke after transient ischaemic attack: a multicentre observational study. The Lancet Neurology 9:10601069

21. Dawson J, Lamb KE, Quinn TJ, Lees KR, Horvers M, Verrijth MJ, Walters MR (2009) A recognition tool for transient ischaemic attack. Qjm 102:43-49

22. Shono K, Satomi J, Tada Y, Kanematsu Y, Yamamoto N, Izumi Y, Kaji R, Harada M, Nagahiro S (2017) Optimal timing of diffusionweighted imaging to avoid false-negative findings in patients with transient ischemic attack. Stroke 48:1990-1992

23. van Rooij FG, Vermeer SE, Góraj BM, Koudstaal PJ, Richard E, de Leeuw FE, van Dijk EJ (2015) Diffusion-weighted imaging in transient neurological attacks. Ann Neurol 78:1005-1010

24. Lee SH, Nah HW, Kim BJ, Ahn SH, Kim JS, Kang DW, Kwon SU (2017) Role of perfusion-weighted imaging in a diffusionweighted-imaging-negative transient ischemic attack. Journal of Clinical Neurology 13:129

Publisher's note Springer Nature remains neutral with regard to jurisdictional claims in published maps and institutional affiliations. 